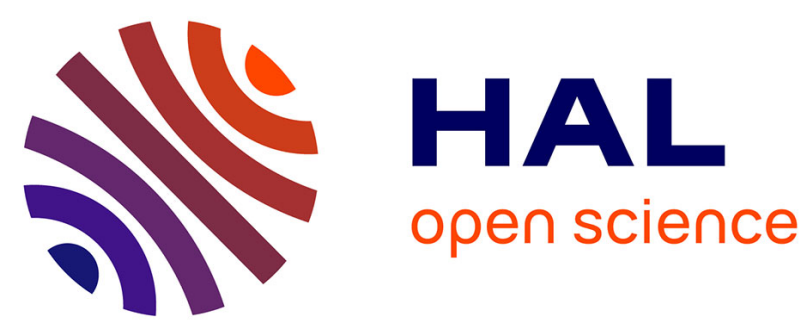

\title{
Thermal Transport Properties of New Coatings on Steels for Supercritical Steam Power Plants
}

\author{
G. Boissonnet, C. Boulesteix, G. Bonnet, J. Balmain, F. Pedraza
}

\section{To cite this version:}

G. Boissonnet, C. Boulesteix, G. Bonnet, J. Balmain, F. Pedraza. Thermal Transport Properties of New Coatings on Steels for Supercritical Steam Power Plants. Oxidation of Metals, 2017, 88 (1-2), pp.191-202. 10.1007/s11085-016-9682-4 . hal-02542023

\section{HAL Id: hal-02542023 \\ https://hal.science/hal-02542023}

Submitted on 14 Apr 2020

HAL is a multi-disciplinary open access archive for the deposit and dissemination of scientific research documents, whether they are published or not. The documents may come from teaching and research institutions in France or abroad, or from public or private research centers.
L'archive ouverte pluridisciplinaire HAL, est destinée au dépôt et à la diffusion de documents scientifiques de niveau recherche, publiés ou non, émanant des établissements d'enseignement et de recherche français ou étrangers, des laboratoires publics ou privés. 


\title{
Thermal Transport Properties of New Coatings on Steels for Supercritical Steam Power Plants
}

\author{
G. Boissonnet, C. Boulesteix, G. Bonnet, J. Balmain, F. Pedraza \\ Laboratoire des Sciences de l'Ingénieur pour l'Environnement - Université de La Rochelle (LaSIE, UMR-CNRS 7356), Avenue \\ Michel Crépeau, 17042 La Rochelle Cedex 1, France \\ germain.boissonnet@univ-lr.fr; claire.boulesteix@univ-lr.fr; gbonnet@univ-lr.fr; jbalmain@univ-lr.fr; fpedraza@univ-lr.fr
}

\begin{abstract}
In order to protect steels from oxidation and corrosion under steam and fireside exposures for the next generation of steam turbines, different protective coatings (slurry Al, pack Al, thermal spray CoNiCrAlY, HIPIMS CrN/NbN, sol-gel $\mathrm{Al}_{2} \mathrm{O}_{3} / \mathrm{AlPO}_{4}$ ) were deposited on ferritic-martensitic P92 and austenitic HR3C steels. Cyclic oxidation in air at $650{ }^{\circ} \mathrm{C}$ and $700^{\circ} \mathrm{C}$ was subsequently conducted for the coatings to grow oxide scales. The thermal transport properties of both the as-deposited and the oxidised coatings were investigated by laser flash analysis till $900^{\circ} \mathrm{C}$ to ascertain whether they inferred any potential harmful insulation to the underlying steel substrate. The results indicated that neither the coatings nor their oxides had any impact on the thermal diffusivity in the temperature range of interest. The thermal diffusivity values were mostly dictated by those of the substrate. It is thus expected that the influence on the thermal transport properties of the coatings under steam conditions will be equivalent than in air.
\end{abstract}

Keywords: Steels, Coatings, Oxidation, Thermal diffusivity

\section{Introduction}

An increase in efficiency and a reduction in greenhouse gas emissions in power generation can be achieved through advanced ultra-supercritical (A-USC) steam turbines operating at up to $760^{\circ} \mathrm{C}$ and 340 bars [1]. From a mechanical standpoint, two different steels have already been selected for their creep strength at the temperature of interest. Ferritic-martensitic P92 was chosen for applications at up to $650^{\circ} \mathrm{C}$, and austenitic HR3C for higher temperatures [2]. However, from the corrosion standpoints, these steels are vulnerable to oxidation attack under ultra-supercritical conditions. For example, low chromium content alloys like P92 ( $<10$ wt.\% Cr) develop a thick oxide scale composed of $\mathrm{Fe}_{2} \mathrm{O}_{3}, \mathrm{Fe}_{3} \mathrm{O}_{4}$ and $(\mathrm{Fe}, \mathrm{Cr})_{3} \mathrm{O}_{4}$ under steam oxidation at $650-700^{\circ} \mathrm{C}$ [3]. For high chromium content alloys like austenitic stainless HR3C, G.R. Holcomb [4] underlined the possibility to form chromium oxo-hydroxide scales under A-USC steam conditions due to decomposition of the water molecule that maintains a constant level of $\mathrm{O}_{2}(\mathrm{~g})$. For chromia-formers, this means that the formation of a non-protective oxide would occur 
faster under these supercritical conditions than in steam critical conditions [5], hence reducing the lifetime of such steels.

The formation of oxide scales has several consequences for the functional behaviour of components. A thick oxide layer has a high tendency to spall, leading to erosion and blockage of downstream components, and also to overheating as it could reduce steam flow [6,7]. Overheating can also be induced by the thermal insulation effect of an oxide scale which could reduce the heat transfer across the component wall. For the raw substrate, a $0.2 \mathrm{~mm}$ oxide scale could lead to an increase of $50^{\circ} \mathrm{C}$ in the temperature of the material, inducing a reduction in the stress rupture life of the substrate by a factor of 40 [6].

In order to avoid the development of oxide scales in such aggressive environments, new protective coatings were studied for P92 and HR3C within the context of the European project "POEMA" so as to provide corrosion and oxidation protection for both steam and fire-side environments [8]. In this way, different coatings deposited through a wide selection of well-known techniques are being tested, i.e. HVOF, HIPIMS, slurry route, pack cementation and sol-gel. Nevertheless, the impacts on the thermal properties of either the coatings or the oxide scales grown from such coatings have not been evaluated yet. Therefore, the thermo-physical properties of the studied coatings before and after thermal ageing must be analysed.

The determination of thermal conductivity of coatings has been widely studied for thermal barrier applications. The calculations have been mostly made using the laser flash analysis (LFA) because of its relative simplicity and accuracy over a wide range of temperature [9]. Thermal conductivity is calculated following the equation:

$$
\lambda=\alpha \times \rho \times C_{p}
$$

where $\alpha$ is the thermal diffusivity measured by the laser flash technique, $\rho$ is the bulk density of the sample and $C_{p}$ is the specific heat calculated by Differential Scanning Calorimetry (DSC) [10]. This means that the accuracy of the calculated thermal conductivity is limited by the uncertainties of the different factors related to equation (1). The coatings provided by the different partners of POEMA were made on P92 substrate in order to be compared with the uncoated substrate itself. Because of their microstructure, the coatings can be considered as multi-layer systems (see Table 1). However, in the case of multiple layers, all thermal properties including density, specific heat capacity, and accurate thicknesses are needed for each layer in order to calculate the thermal conductivity. The density and specific heat capacity of each of these sublayers are unknown and cannot be calculated using traditional methods (respectively, by dilatometric and calorimetric methods) due to the very low thickness of such 
sublayers. Moreover, Taylor et al. carried out sensitivity studies in laser flash experiments on two-layer samples for thermal barrier coatings $[9,11]$. They highlighted the importance of the input parameters in the calculated values of thermal conductivity. For example, the determination of thermal diffusivity of thin coatings could be irrelevant due to the lack of representative quantity of the material. Consequently, with poor knowledge of the characteristics of thicknesses, density and specific heat of all the different coatings in the study, thermal conductivity calculations may be not accurate enough.

However, to make a comparative study of the different coatings and to evaluate their impact on thermal insulation, it is possible to use the thermal diffusivity route. As the thermal diffusivity represents the rate of heat propagation by conduction, it could be used to assess the difference of thermal transport properties of the coated substrates. In this way, the conversion of diffusivity values to conductivity values is not of major concern, and the diffusivity, specific heat, density route is usually more accurate than thermal conductivity determinations.

Therefore, this work focuses on the assessment of potential changes induced by different coatings in the thermal diffusivity of a P92 ferritic-martensitic steel substrate in the as-deposited condition and after oxidation at $650^{\circ} \mathrm{C}$. Like Aguiero et al. proposed, cyclic oxidation in air will be employed to induce potential cracking of the scales and/or of the coatings [12] instead of steam. Further insight is provided for the slurry aluminised austenitic $\mathrm{HR} 3 \mathrm{C}$ steel oxidised at $700^{\circ} \mathrm{C}$ as it appears as very promising for long term oxidation resistance in steam [13].

\section{Experimental Procedures}

\subsection{Materials and Coatings}

Ferritic-martensitic P92 (0.1 C, 0.5 Mn, 0.03 Si, 8.8 Cr, 0.06 Ni, 0.4 Mo, 1.8 W, 0.2 V, wt.\%, bal. Fe) and austenitic stainless HR3C (0.06 C, 1.2 Mn, 0.4 Si, 25.0 Cr, $20.0 \mathrm{Ni}, 0.45 \mathrm{Nb}, 0.2 \mathrm{~N}$, wt.\%, bal. Fe) steels were employed as substrates (nominal compositions are given). The dimensions of P92 and HR3C samples were 10x10x2 $\mathrm{mm}^{3}$ for laser flash measurements. The samples were coated in different ways by the partners of the POEMA project and sent to the University of La Rochelle for being tested. The different coatings and their characteristics are listed in Table 1.

Table 1 - Different types of coatings deposited on P92 substrate.

\begin{tabular}{|c|c|c|c|c|c|c|}
\hline & $\mathrm{Al}, \mathrm{s}$ & $\mathrm{Al}, \mathrm{p}$ & CoNiCrAlY & $\mathrm{CrN} / \mathrm{NbN}$ & $\mathrm{Al}_{2} \mathrm{O}_{3} / \mathrm{AlPO}_{4}$ \\
\hline \multicolumn{2}{|c|}{ Technique } & Slurry coating & pack cementation & HVOF PVD & HIPIMS PVD & $\begin{array}{l}\text { Sol-gel successive } \\
\text { depositions }\end{array}$ \\
\hline \multirow[t]{2}{*}{ Features } & $\begin{array}{l}\text { As- } \\
\text { deposited }\end{array}$ & $\begin{array}{l}\text { Diffusion coating } \\
\mathbf{6 0} \boldsymbol{\mu m} \\
\text { (additive layer) }\end{array}$ & $\begin{array}{l}\text { Diffusion coating } \\
\mathbf{4 0} \boldsymbol{\mu m} \\
\text { (additive layer) }\end{array}$ & $\begin{array}{l}\text { Overlay } \\
\mathbf{3 7 0} \boldsymbol{\mu m}\end{array}$ & $\begin{array}{l}\text { Overlay } \\
2.5 \mu \mathrm{m}\end{array}$ & $\begin{array}{l}\text { Co-overlays, } 0.4- \\
1.6 \mu \mathrm{m}(\text { boehmite }) \\
+\mathbf{1 0} \mu \mathrm{m}\left(\mathrm{AlPO}_{4}\right)\end{array}$ \\
\hline & $\begin{array}{l}\text { After } \\
\text { thermal } \\
\text { ageing }\end{array}$ & $\begin{array}{l}\text { Al consumption by } \\
\text { diffusion } \\
\mathbf{3 5} \boldsymbol{\mu m} \\
\text { (additive layer) }\end{array}$ & $\begin{array}{l}\text { Al consumption } \\
\text { by diffusion } \\
\mathbf{2 0} \boldsymbol{\mu m} \\
\text { (additive layer) }\end{array}$ & $\begin{array}{l}\text { Shrinkage/sintering } \\
\mathbf{2 7 0} \boldsymbol{\mu m} \\
\text { (not the same batch) }\end{array}$ & $\begin{array}{l}\text { Spalled or } \\
\text { oxidized layer } \\
0-2 \mu \mathrm{m}\end{array}$ & $\begin{array}{l}\text { Continuous } \\
\text { overlay, } \\
\mathbf{0 . 2 5}-\mathbf{0 . 8} \boldsymbol{\mu m}\end{array}$ \\
\hline
\end{tabular}




\subsection{Thermal Cycling}

Studies conducted on slurry aluminized Inconel 800HT (stainless steel whose composition is close to that of HR3C) showed that the degradation rate of the aluminide coating was greater in air than in steam [13]. In order to characterize the thermal properties of the different oxide scales, thermal cycling in air similar to the one conducted by Agüero et al. [12] was performed to promote the growth of the oxide scales and the potential cracking of both the scales and the coatings, i.e. to induce defects that may affect their thermal conductivity. The thermal cycles consisted of $1 \mathrm{~h}$ heating to maintain the samples at $650{ }^{\circ} \mathrm{C}$ or $700^{\circ} \mathrm{C}$, for $\mathrm{P} 92$ and $\mathrm{HR} 3 \mathrm{C}$ respectively, followed by $5 \mathrm{~min}$ cold period at room temperature. Mass change was recorded up to 1100 cycles.

\subsection{Methods of Characterization}

The thermal diffusivity of bulk P92 and coated samples was measured using the laser flash method [10] with a Linseis LFA 1600 apparatus. The thermal diffusivity measurements of the samples were conducted under vacuum from room temperature to $900^{\circ} \mathrm{C}$. For a reasonable accuracy of the measurements, three samples were simultaneously analysed and the thermal diffusivity was calculated from the average of the three values. Before and after thermal ageing, the coatings were characterized by scanning electron microscopy (SEM, FEI Quanta 200F/EDAX) and the $C_{p}$ of the P92 substrate was measured by a Differential Scanning Calorimeter (DSC Labsys Evo TGA SETARAM).

\section{Results and Discussion}

\subsection{Thermal Cycling in air}

Figure 1 depicts the evolution of the specific mass with the number of 1 h-cycle exposed to air at $650^{\circ} \mathrm{C}$ for the different coated substrates as well as the uncoated ones. All the mass changes of the coated samples are very low except for the $\mathrm{CrN} / \mathrm{NbN}$ coating that exhibits a mass loss that corresponds to the delamination observed on the figure $\mathbf{2 a}$ described later.

Table 1 and figure 2 gather the coatings obtained from the different coaters and their characteristics before and after thermal ageing. Two types of coatings could be distinguished from their structure: overlays and diffusion coatings.

$\mathrm{CrN} / \mathrm{NbN}$ and $\mathrm{Al}_{2} \mathrm{O}_{3} / \mathrm{AlPO}_{4}$ are thin overlays with thicknesses ranging from $1 \mu \mathrm{m}$ to $3 \mu \mathrm{m}$, whereas CoNiCrAlY is a thick overlay of more than $300 \mu \mathrm{m}$ containing micro-porosities due to the HVOF method employed. Figure $\mathbf{2 h}$ shows that the porosities in the latter have been sealed by sintering during thermal ageing and that oxidation occurred (darker areas). Moreover, a large difference in coating thickness is observed before and after thermal ageing. However, it should be noticed that the two SEM micrographs 
were not realized on the same sample and that the large difference of thickness may not only be due to the shrinkage of the overlay during thermal ageing. Concerning the $\mathrm{Al}_{2} \mathrm{O}_{3} / \mathrm{AlPO}_{4}$ coating (figure $\mathbf{2 b}$ and $\mathbf{2 g}$ ), the $\mathrm{AlPO}_{4}$ used as a sealant for the $\mathrm{Al}_{2} \mathrm{O}_{3}$ layer is no more observed after ageing. Nevertheless, the coating seems to have been efficient as no oxide scale, other than the coating itself, is observed. The $\mathrm{CrN} / \mathrm{NbN}$ coating (figure 2a) formed a thick and brittle oxide layer that easily spalled off during cycling. No thick oxide scale coming from the substrate itself was detected either.

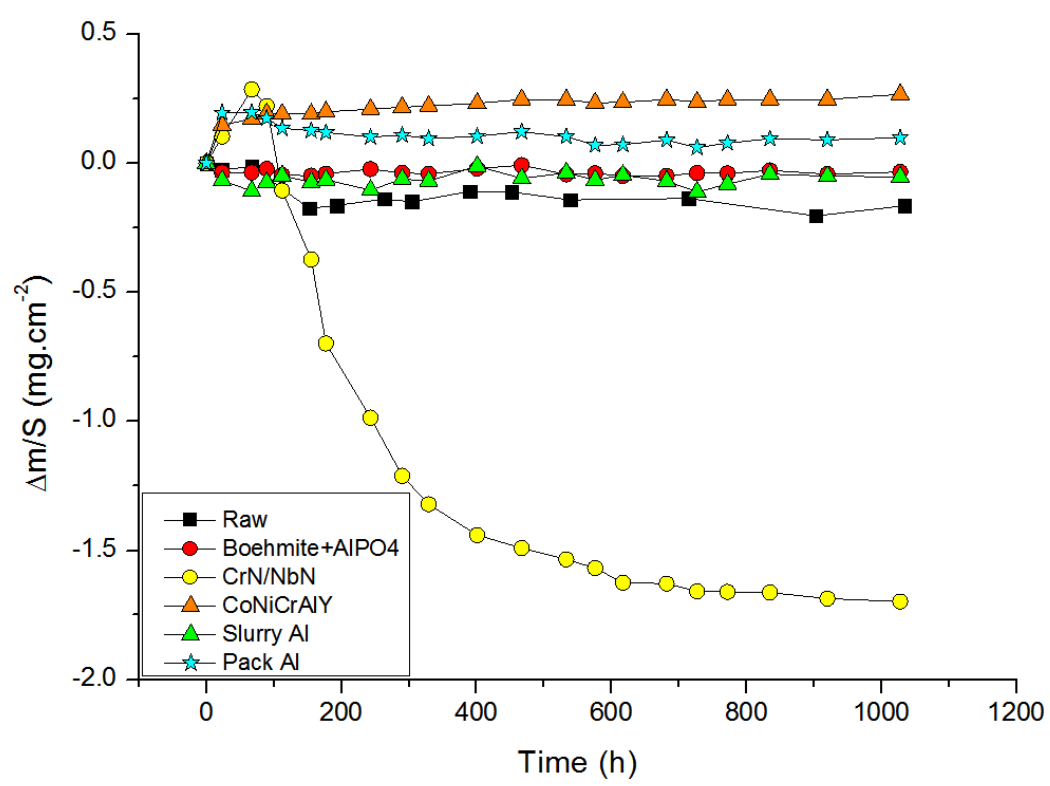

Figure 1 -Evolution of the specific mass gain of uncoated and coated substrates exposed to air for 1h-cycles at $650^{\circ} \mathrm{C}$.

For the diffusion coatings, the slurry and the pack cementation techniques result in two very different aluminide coatings. The slurry Al (figure 2d) leads to a thick additive zone of $60 \mu \mathrm{m}$ on top of a $75 \mu \mathrm{m}$ inter-diffusion zone containing AlN precipitates. The rough surface of the coating is due to the grit blasting cleaning carried out in order to remove the empty alumina shells after the thermal treatment of the coating formation [14]. During ageing, the additive layer loses Al by diffusion in the substrate (figure 2i) as the additive layer appears brighter and thinner, and no thick oxide scale is observed on the surface of the coating. Although the pack aluminized substrate (figure 2e) presents a non-homogeneous additive layer with cracks, no thick oxide scale is detected either on the surface after ageing (figure $\mathbf{2} \mathbf{j}$ ) and only a reduction of the thickness of the additive layer by inward diffusion of $\mathrm{Al}$ is observed.

For the uncoated P92 substrate, only a thin oxide scale of $2 \mu \mathrm{m}$ was observed after ageing (figure $\mathbf{2 k}$ and 2l), indicating that the P92 substrate forms a protective oxide scale under the conditions of thermal cycling [15]. The bright precipitates observed in the substrate were associated with heavy elements segregated at the grain boundaries. 

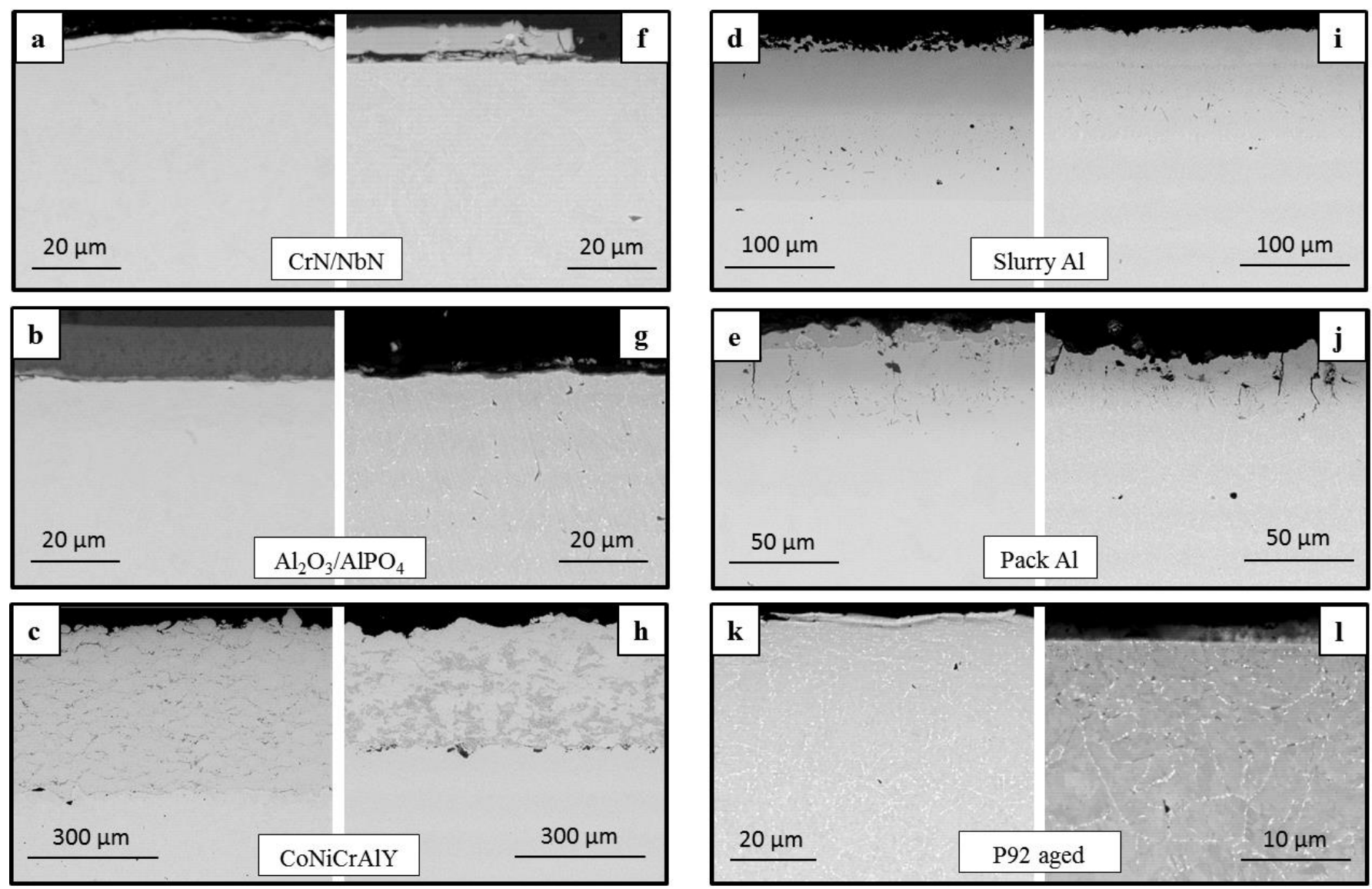

Figure 2 - SEM Micrographs of cross sections of the different coatings on P92 in as-deposited condition ( $a, b, c, d$, $e)$, after thermal ageing $(f, g, h, i, j)$ and the uncoated substrate after thermal ageing $(k)$ and with higher contrast and magnification (l).

\subsection{Thermal Diffusivity Measurements}

\subsubsection{Before Thermal Cycling}

Figure 3a shows the measured thermal diffusivity values of the P92 steel, uncoated and coated in the as-deposited conditions, as a function of temperature ranging from room temperature till $900^{\circ} \mathrm{C}$. For all measurements, the thermal diffusivity of the coated samples follows the tendency of the substrate despite some deviations for CoNiCrAlY, slurry $\mathrm{Al}$ and pack $\mathrm{Al}$ (described later with figure 3b). From room temperature to $700^{\circ} \mathrm{C}$, the thermal diffusivity decreases and then increases up to $900^{\circ} \mathrm{C}$.

This phenomenon is due to a change in the magnetic properties of the substrate which was highlighted by differential scanning calorimetry (DSC) in figure 4, where the specific heat capacity of the P92 is plotted against temperature. Two exothermic peaks are detected at $760^{\circ} \mathrm{C}$ and $875^{\circ} \mathrm{C}$ that respectively correspond to the Curie's transformation (magnetic to paramagnetic) and to the ( $\alpha$-ferrite + carbides) to $\gamma$ austenite phase transformation [16,17]. Since the component of heat transport by electrons is an important factor in the thermal conductivity of metallic substrates, the loss of the magnetic properties observed by DSC logically results in a change of heat transport behaviour [18]. 
Figure 3b represents the difference (expressed in \%) of thermal diffusivity between the uncoated substrate and the coated substrates. For slurry Al and CoNiCrAlY coatings, the diffusivity is $20-25 \%$ lower than that of the uncoated substrate. This difference decreases with temperature till less than $5 \%$ beyond $600^{\circ} \mathrm{C}$. However, for the pack $\mathrm{Al}$ coating, the differences remain about 5 to $10 \%$ higher than that of the substrate. For all the other coatings, the differences do not exceed 5\% between room temperature and $900^{\circ} \mathrm{C}$.

The difference of thermal diffusivity for slurry $\mathrm{Al}$ and CoNiCrAlY coatings indicates that these coatings lower the thermal transport till $600^{\circ} \mathrm{C}$ but also shows that the impact of the coating slowly decreases while temperature increases to attain less than $5 \%$ of difference with respect the substrate. This implies that the coatings increase the thermal resistance of the substrate at low temperatures. For $\mathrm{CoNiCrAlY}$ and the Al slurry, the presence of micro-porosities in the coating can be responsible for the lower thermal diffusivity values. These values are though constantly higher for the pack aluminized coatings, which could be due to a microstructural modification of the substrate upon the pack aluminizing
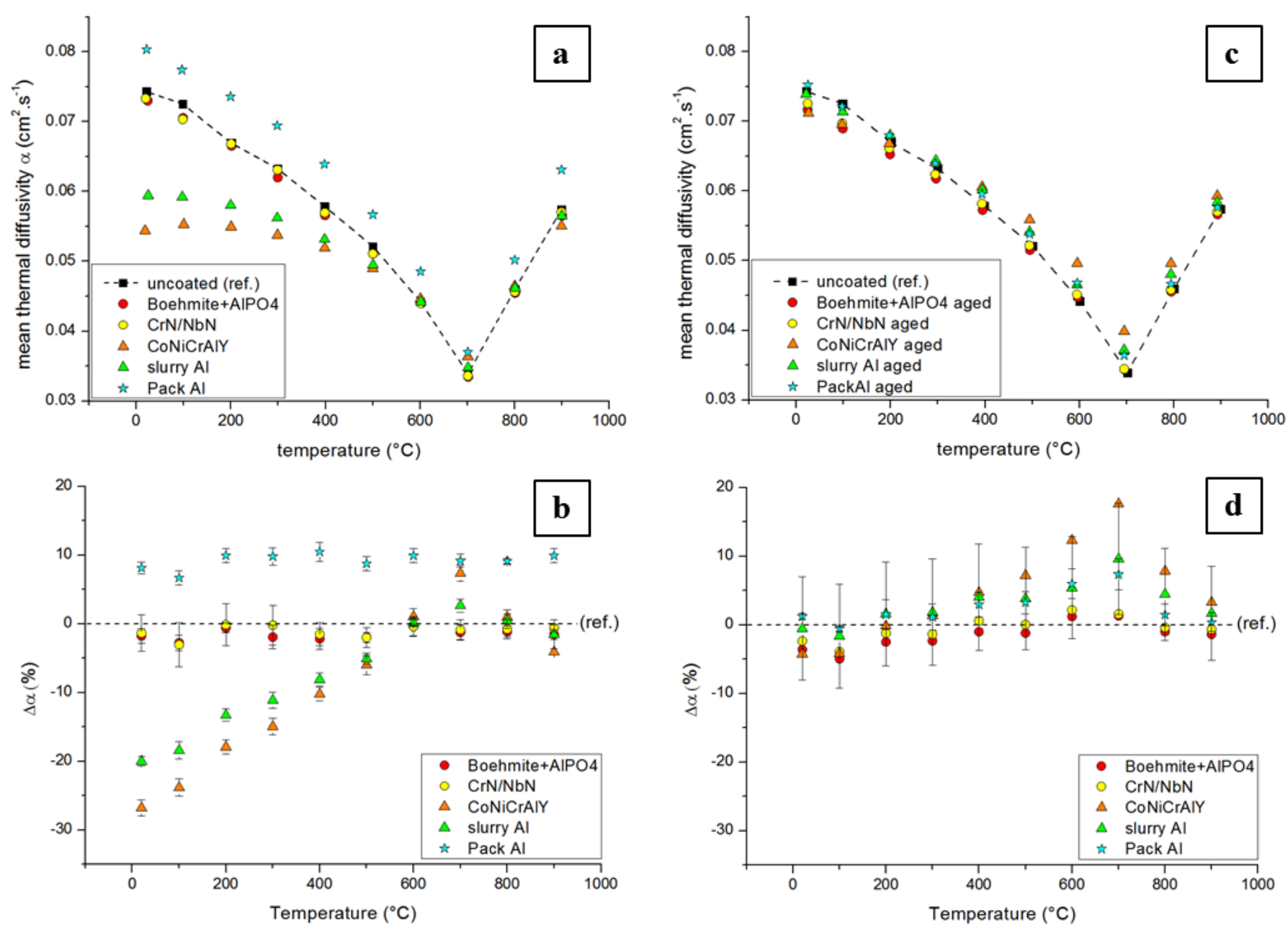

Figure 3 - Thermal diffusivity values of coated and uncoated P92 samples as a function of temperature (a) in the as-deposited conditions and (c) after thermal ageing. $(b)$ and $(d)$ are, respectively, the differences of thermal diffusivity between the uncoated (ref.) and the coated substrates in the as-deposited condition and after thermal ageing. 
process. Indeed, several hours at high temperature followed by a slow cooling may modify the steel microstructure resulting in a grain growth [14]. The resulting microstructure will cause a significant decrease of grain boundaries which are responsible for phonon-phonon scattering that could lead to an increase in thermal diffusivity [19].

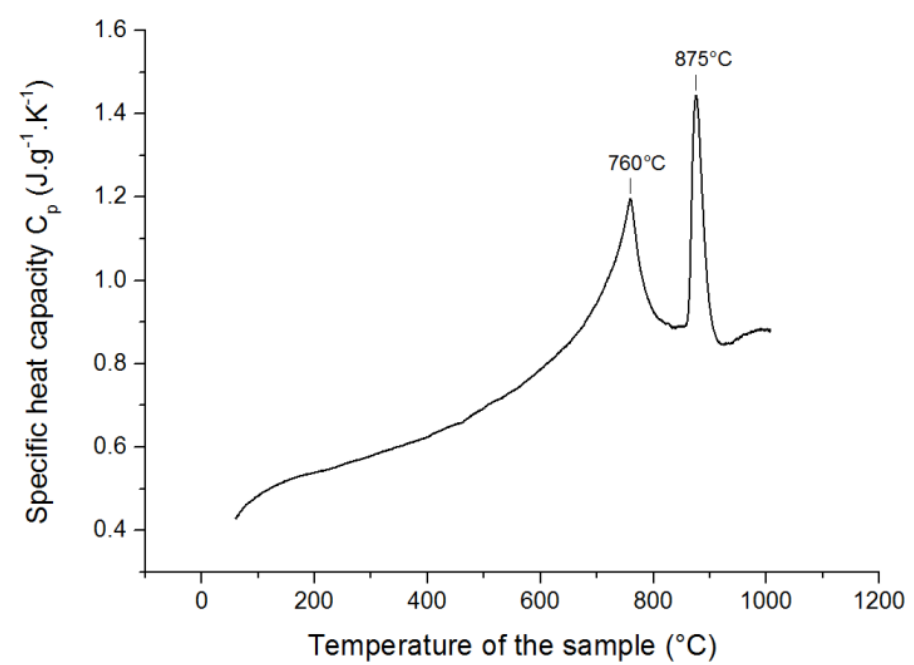

Figure 4 - Specific heat capacity of P92 measured by DSC as a function of the temperature.

\subsubsection{After Thermal Cycling}

Figure 3c shows the thermal diffusivity as a function of temperature between room temperature and $900^{\circ} \mathrm{C}$ of the uncoated and coated samples after thermal cycling. Figure 3d shows the differences in thermal diffusivity (expressed in \%) between the reference substrate and the aged coatings. Ageing very clearly resulted in much closer values to the unaged and uncoated P92 steel when compared to the unaged coatings.

The apparent homogenization of the values of the coated samples could be explained by the loss of the porosities for slurry $\mathrm{Al}$ and CoNiCrAlY coatings upon ageing (diffusion). Therefore, the thermal diffusivity values seem to be influenced by the substrate rather than by the coatings themselves. This phenomenon is probably due to the homogenization of the substrate of the different samples as they all underwent the same cyclic ageing. An additional proof to support this hypothesis is that the higher thermal diffusivity values of pack Al before ageing became closer to those of the other coated samples after thermal ageing. Indeed, B. Jeyaganesh et al. explained that microstructural changes during thermal ageing at $550^{\circ} \mathrm{C}$ and $650^{\circ} \mathrm{C}$ in $9 \mathrm{Cr}-1 \mathrm{Mo}-0.1 \mathrm{C}$ (mass \%) steel have an impact on the measured specific heat capacity [16]. During thermal ageing, the relaxation of the martensite laths by diffusion of carbides results in the gradual development of a $\alpha$-ferrite strain-free matrix and $\mathrm{M}_{23} \mathrm{C}_{6}$ carbide precipitation that comes out under equilibrium conditions at $650{ }^{\circ} \mathrm{C}$. Carbide precipitates can be observed at the grain boundaries (bright dots) on the micrographs of the different samples after thermal ageing (figure 2l). This 
slow transformation of the matrix to a strain-free structure with fewer defects could explain the change in thermal transport capacity by facilitating phonon-phonon vibration [19].

\subsection{HR3C Substrate}

Figure 5a displays the thermal diffusivity values of uncoated and slurry $\mathrm{Al}$ coated HR3C substrate. Figure $4 \mathbf{b}$ shows that the difference in $\%$ of thermal diffusivity between both is negligible. The reasons for the greater thermal diffusivity of the Al slurry on P92 than the Al slurry on HR3C against their respective substrates likely arise from the coating thicknesses and microstructures. Indeed, whereas the $\mathrm{Al}$ slurry on P92 is about $135 \mu \mathrm{m}$ thick and contains micro-porosities (see Figure 2), the Al slurry on HR3C is thinner (about $60 \mu \mathrm{m}$ thick) and appears more compact (Figure 6). This is in accordance with the previous assumption that the contribution of the substrate predominates in the thermal diffusivity due to its greater thickness $(2 \mathrm{~mm}$ ) against that of the coatings (maximum $300 \mu \mathrm{m}$ for CoNiCrAlY by HVOF). In addition, the ferritic-martensitic matrix is more sensitive to microstructural changes upon thermal ageing than $\mathrm{HR} 3 \mathrm{C}$ in the experimental conditions studied here.
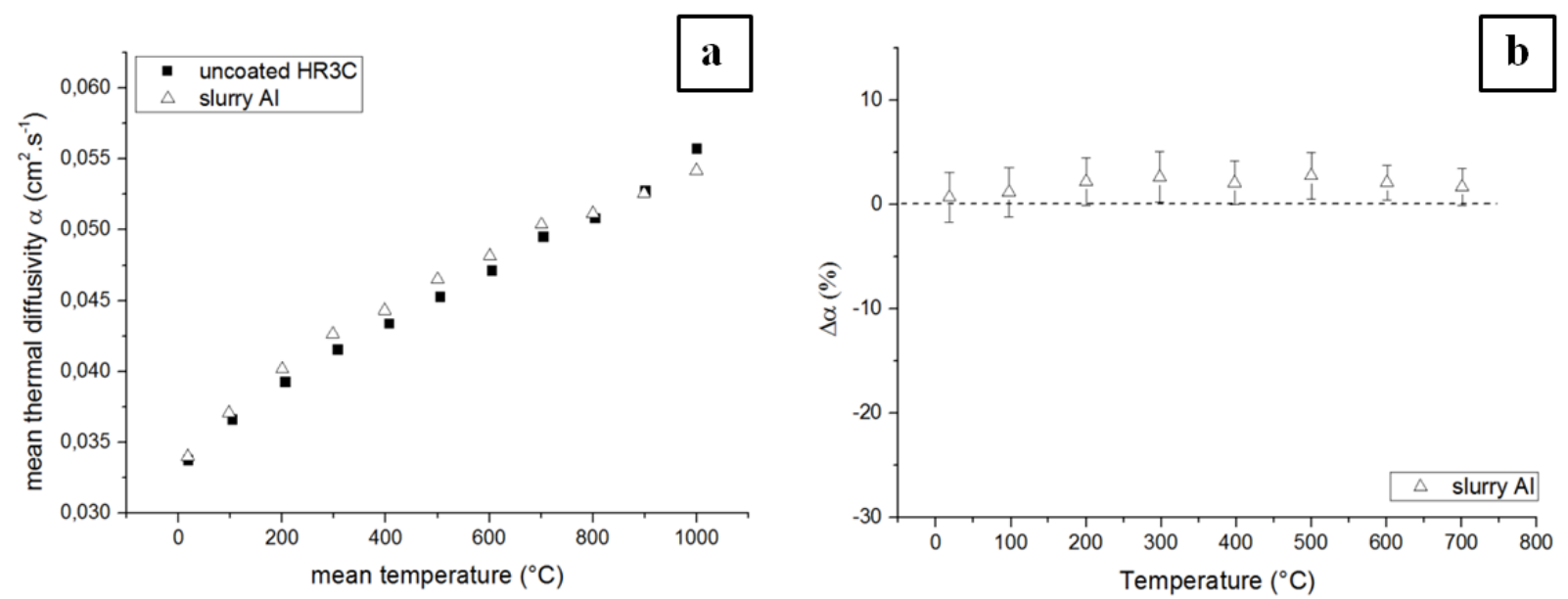

Figure 5 - (a) Thermal diffusivity values of uncoated and slurry Al coated HR3C samples as a function of temperature and (b) thermal diffusivity difference between uncoated (dash-line) and slurry aluminized HR3C.

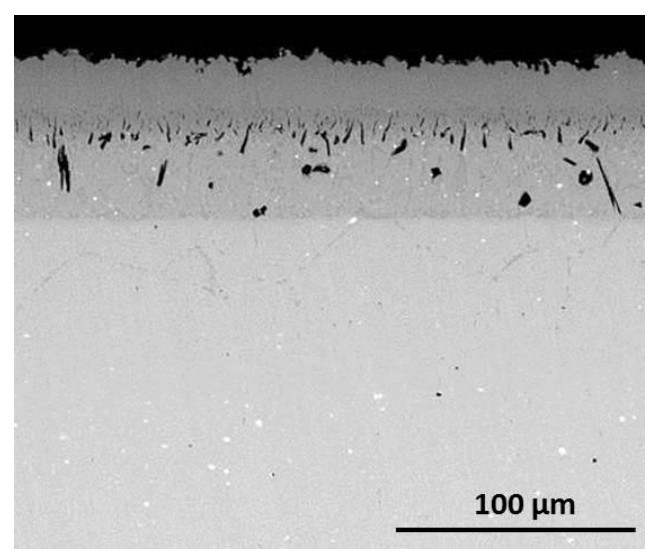

Figure 6 - SEM cross-section of the Al slurry coatings on HR3C austenitic stainless steel. 


\section{CONCLUSIONS}

The thermal diffusivities of various coatings (slurry Al, pack Al, thermal spray CoNiCrAlY, HIPIMS $\mathrm{CrN} / \mathrm{NbN}$, sol-gel $\mathrm{Al}_{2} \mathrm{O}_{3} / \mathrm{AlPO}_{4}$ ) in the as-deposited conditions and after thermal cyclic oxidation were relatively similar to those of the uncoated and unaged P92 and HR3C steel substrates. The major differences were found in the as-deposited coatings and at low temperatures. As the temperature was increased in the laser flash apparatus, the thermal diffusivity was within 5\% of difference in the P92 substrate. The oxidation in air of the coatings at $650^{\circ} \mathrm{C}$ for 1100 cycles did not result in the formation of thick oxide scales and therefore, their effect on thermal diffusivity was negligible. In HR3C the Al slurry coatings barely modified the thermal diffusivity even in the oxidised conditions. The differences in the effects of the coatings in P92 and in HR3C on the thermal diffusivity appear thus nil. The differences are in fact explained by changes in the microstructure of the substrates, which can be considerable in P92 but negligible in $\mathrm{HR} 3 \mathrm{C}$ at least in the conditions tested here. It is thus expected that their impact will be also nil under steam oxidising conditions. Further investigations with steam oxidised samples would be interesting for a comparison with the coatings oxidised in air.

\section{ACKNOWLEDGEMENTS}

The authors gratefully acknowledge European Union for the funding of FP7 project "POEMA: Production of Coatings for New Efficient and Clean Coal Power Plant Materials" (Grant agreement no. 310436). Turbocoating, Sheffield Hallam University, BAM and the Chuiko Institute of Surface Chemistry are greatly indebted for supplying the pack Al and CoNiCrAlY, the HIPIMS CrN/NbN and the $\mathrm{Al}_{2} \mathrm{O}_{3} / \mathrm{AlPO}_{4}$ hybrid sol-gel coatings, respectively. 


\section{REFERENCES}

1. G. R. Holcomb, Journal of the Electrochemical Society 156, C292 (2009).

2. R. Viswanathan, Advanced Materials and Processes 162, 73 (2004).

3. A. Agüero, Energy Materials 3, 35 (2008).

4. G.R. Holcomb, Oxidation of Metals 69, 163 (2008).

5. D. J. Young and B. A. Pint, Oxidation of Metals 66, 137 (2006).

6. P. J. Ennis and W. J. Quadakkers, International Journal of Pressure Vessels and Piping 84, 82 (2007).

7. W. Schulz and A. Kranzmann in NACE international corrosion conference \& expo, "Comparison of the corrosion behaviour of 9-12\% Cr steels in $\mathrm{H}_{2} \mathrm{O}, \mathrm{H}_{2} \mathrm{O}-\mathrm{CO}_{2}$ and $\mathrm{H}_{2} \mathrm{O}-\mathrm{CO}_{2}-\mathrm{O}_{2}$ " (2009).

8. http://cordis.europa.eu/project/rcn/106505_en.html, Accessed to 25 Jan. 2016.

9. R.E Taylor, X. Wang and X. Xu, Surface and Coatings Technology 120-121, 89 (1999).

10. ASTM E1461-11, "Standard test method for Thermal Diffusivity by the Flash Method" (2011).

11. R.E. Taylor, Materials and Science Engineering A245, 160 (1998).

12. A. Agüero, R. Muelas, M. Gutiérrez, R. Van Vulpen, S. Osgerby and J.P. Banks, Surface and Coatings Technology 201, 6253 (2007).

13. F. Pedraza, M. Proy, C. Boulesteix, P. Krukovskyi and M. Metel, Materials and Corrosion 67, 1059 (2016).

14. A. Agüero, M. Gutiérrez, R. Muelas, Material Science Forum 522-523, 205 (2006).

15. I. G. Wright and B. A. Pint, NACE 02-377, NACE Corrosion 2002, Denver, CO, March (2002).

16. B. Jeyaganesh, International Journal of Thermophysics 30, 619 (2009).

17. S. Raju, Journal of Nuclear Materials 389, 385 (2009).

18. Y. S. Touloukian, R. W. Powell, C. Y. Ho and P. G. Klemens, "Thermophysical properties of matter” in Thermal conductivity-volsl \&2, IFI/Plenum, NY, 1970.

19. L. Pawlowski and P. Fauchais, International Materials Reviews 37, 6, 271 (1992). 